\title{
Influence of mixtures of acenaphthylene and benzo[a] anthracene on their degradation by Pleurotus ostreatus in sandy soil
}

\author{
Inês Rocha • Edgar Pinto • Isabel M. P. L. V. O. Ferreira • \\ Manuela V. da Silva $•$ Rui S. Oliveira
}

Received: 1 August 2013 / Accepted: 28 October 2013 / Published online: 13 November 2013

(C) Springer-Verlag Berlin Heidelberg 2013

\begin{abstract}
Purpose Polycyclic aromatic hydrocarbons (PAHs) are a class of organic compounds commonly found as soil contaminants. Fungal degradation is considered as an environmentally friendly and cost-effective approach to remove PAHs from soil. Acenaphthylene (Ace) and Benzo[a]anthracene (BaA) are two PAHs that can coexist in soils; however, the influence of the presence of each other on their biodegradation has not been studied. The biodegradation of Ace and BaA, alone and in mixtures, by the white rot fungus Pleurotus ostreatus was studied in a sandy soil.

Materials and methods Experimental microcosms containing soil spiked with different concentrations of Ace and BaA were inoculated with $P$. ostreatus. Initial $\left(t_{0}\right)$ and final (after 15 days of incubation) soil concentrations of Ace and BaA were determined after extraction of the PAHs.
\end{abstract}

Responsible editor: Jaume Bech

I. Rocha $\cdot$ M. V. da Silva $\cdot$ R. S. Oliveira $(\square)$

CISA/School of Allied Health Sciences, Polytechnic Institute of

Porto, Rua Valente Perfeito, 322, 4400-330 Vila Nova de Gaia,

Portugal

e-mail: rso@estsp.ipp.pt

E. Pinto • I. M. P. L. V. O. Ferreira

REQUIMTE, Laboratório de Bromatologia e Hidrologia,

Departamento de Ciências Químicas, Faculdade de Farmácia,

Universidade do Porto, Rua Jorge Viterbo Ferreira, 4050-313

Porto, Portugal

R. S. Oliveira

Centre for Functional Ecology, Department of Life Sciences,

University of Coimbra, 3000-455 Coimbra, Portugal

\section{R. S. Oliveira}

CBQF - Centro de Biotecnologia e Química Fina - Laboratório

Associado, Escola Superior de Biotecnologia, Universidade Católica

Portuguesa/Porto, Rua Dr. António Bernardino de Almeida,

4200-072 Porto, Portugal
Results and discussion P. ostreatus was able to degrade $57.7 \%$ of the Ace in soil spiked at $30 \mathrm{mg} \mathrm{kg}^{-1}$ dry soil and $65.8 \%$ of Ace in soil spiked at $60 \mathrm{mg} \mathrm{kg}^{-1}$ dry soil. The degradation efficiency of $\mathrm{BaA}$ by $P$. ostreatus was 86.7 and $77.4 \%$ in soil spiked with Ace at 30 and $60 \mathrm{mg} \mathrm{kg}^{-1}$ dry soil, respectively. After 15 days of incubation, there were no significant differences in Ace concentration between soil spiked with Ace and soil spiked with Ace $+\mathrm{BaA}$, irrespective of the initial soil concentration of both PAHs. There were also no differences in $\mathrm{BaA}$ concentration between soil spiked with $\mathrm{BaA}$ and soil spiked with $\mathrm{BaA}+$ Ace.

Conclusions The results indicate that the fungal degradation of Ace and BaA was not influenced by the presence of each other's PAH in sandy soil. Bioremediation of soils contaminated with Ace and $\mathrm{BaA}$ using $P$. ostreatus is a promising approach to eliminate these PAHs from the environment.

Keywords Acenaphthylene $\cdot$ Benzo[a]anthracene ·

Biodegradation · PAHs mixtures · Pleurotus ostreatus .

Polycyclic aromatic hydrocarbons (PAHs)

\section{Introduction}

Polycyclic aromatic hydrocarbons (PAHs) are widespread organic pollutants. They are formed during the incomplete combustion of carbonaceous material, including crude oil, wood, coal, food, motor oil, gasoline, fat, tobacco and incense. PAHs are lipophilic and have low volatility, thus the soil is the environmental compartment where they are ultimately deposited (Bakker et al. 2000). Exposure to PAHs is of concern to human health because they are ubiquitous in the urban environment and because several have been identified as carcinogenic, mutagenic and teratogenic (Rostami and Juhasz 2011). Since the Industrial Revolution, surface soils have been subjected to increases 
in their PAH content (Riding et al. 2013). It has become imperative to eliminate them from such an important and vital environmental compartment. The hazards associated with PAHs can be overcome by the use of conventional physicochemical remediation methods; however, these are expensive, and in many cases, transfer the pollutant from one phase to another. Fungal degradation is often characterised as an environmentally friendly and costeffective approach to remove PAHs from soil (Bhatt et al. 2002; Gao et al. 2010). A number of species of ligninolytic fungi, such as Pleurotus ostreatus, are known to degrade PAHs and the biodegradation rates correlate with the production of ligninolytic enzymes (Bamforth and Singleton 2005; Johnsen et al. 2005).

Acenaphthylene (Ace) (Fig. 1a) is a 3-ring PAH used to manufacture dyes, plastics and pesticides and was found as a constituent of crude oil, coal tar and tobacco smoke. Ace can be released to the environment by emissions from petroleum refining, coal tar distillation, municipal waste incinerators and during natural fires (Meharg et al. 1998). Benzo[a]anthracene (BaA) (Fig. 1b) is a 4-ring PAH commonly found in soils from creosote waste sites, former wood-treating operations, and manufactured gas plant sites (Moody et al. 2005).

Biodegradation of Ace and $\mathrm{BaA}$ has been reported (Majcherczyk et al. 1998; Cajthaml et al. 2006; Nayak et al. 2009; Rosales et al. 2012). However, most investigations of fungal degradation of PAHs have been performed in artificially contaminated liquid media, which results may not be realistically comparable with those obtained in studies conducted in soil (Haritash and Kaushik 2009). Moreover, many studies on the degradation of PAHs have focused on individual compounds, while in most contaminated soils, the PAHs occur in complex mixtures. Beckles et al. (1998) reported that fluoranthene was not degraded when present alone or in combination with Ace but was degraded when combined with naphthalene, demonstrating that the composition of PAHs in soil largely influenced their biodegradation.

Ace and $\mathrm{BaA}$ can coexist in soils (Nadal et al. 2004); however, the influence of the composition of PAHs on their biodegradation has not been studied.

In this context, the aims of the present study were as follows: (1) to assess the capability of biodegradation of Ace and $\mathrm{BaA}$ at different concentrations by the white rot fungus $P$. ostreatus in sandy soil and (2) to evaluate whether the fungal degradation of Ace and $\mathrm{BaA}$ is influenced by the presence of each other PAH.

\section{Materials and methods}

\subsection{Microorganism and preparation of inoculum}

P. ostreatus (Jacq. ex Fr.) P. Kumm. strain PO1 from the collection of the CISA/School of Allied Health Sciences, Polytechnic Institute of Porto, Portugal, was cultivated on malt extract agar at $25^{\circ} \mathrm{C}$ in the dark for 7 days prior to use. Locally purchased sorghum [Sorghum bicolor (L.) Moench] seeds were used as substrate for the preparation of inoculum of $P$. ostreatus. Seeds were washed with deionised water and boiled during $15 \mathrm{~min}$. After draining the water, the $\mathrm{pH}$ of the boiled seeds was adjusted to 8.0 by adding $\mathrm{NaHCO}_{3}$ and mixing thoroughly. The $\mathrm{pH}$ was measured by inserting a $\mathrm{pH}$ electrode (Multiline P3 pH/LF-SET, Germany) on the moist seeds. Seeds were then autoclaved at $121{ }^{\circ} \mathrm{C}$ for $30 \mathrm{~min}$. Two kilogrammes of autoclaved seeds were placed inside a sterile plastic bag and inoculated with six plugs $(2-\mathrm{cm}$ diameter) of malt extract agar with $P$. ostreatus. After 15 days of incubation in the dark at $25^{\circ} \mathrm{C}$, the fungus thoroughly colonised the sorghum seeds. The colonised seeds were homogenised and the inoculum of $P$. ostreatus was ready for further use.

\subsection{Soil characteristics and preparation}

A sandy loam ( $\mathrm{pH} 8.2$, electrical conductivity $93 \mu \mathrm{S} \mathrm{cm} \mathrm{cm}^{-1}$, organic matter $1.4 \%$, total $\mathrm{N} 0.4 \%$, extractable P $15 \mathrm{mg} \mathrm{kg}^{-1}$ ) was autoclaved $\left(121{ }^{\circ} \mathrm{C}, 30 \mathrm{~min}\right)$ twice on consecutive days and then spiked with PAHs solutions. These solutions were prepared by adding appropriate amounts of PAHs to $200 \mathrm{ml}$ of acetone as solvent ( $10 \%$ of soil volume), to obtain the desirable concentrations. After spiking the soil, acetone was evaporated in a fume hood for $30 \mathrm{~min}$.
Fig. 1 Chemical structure of acenaphthylene (a) and benzo[a]anthracene (b)
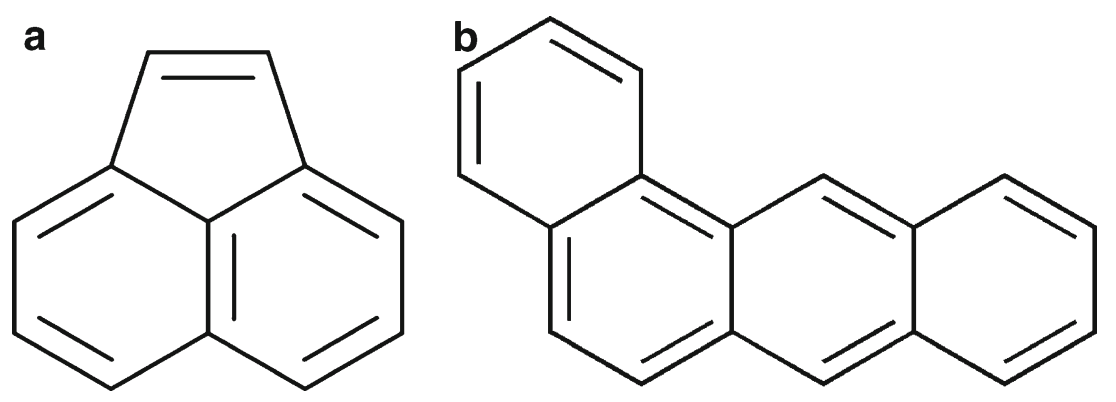


\subsection{Experimental design}

Experimental microcosms were prepared by placing soil spiked with the PAHs inside $1 \mathrm{~L}$ (length $17 \mathrm{~cm}$, width $10 \mathrm{~cm}$, height $6 \mathrm{~cm}$ ) plastic boxes $(650 \mathrm{~g}$ of air-dried soil per box). Each box received a layer of $80 \mathrm{~g}$ of inoculum (sorghum seeds colonised by $P$. ostreatus) and $30 \mathrm{ml}$ of sterile deionised water, which corresponded to $20 \%$ of the water holding capacity of the soil. Non-inoculated control boxes received $80 \mathrm{~g}$ of non-colonised sorghum seeds. Experimental units were arranged in a fully randomised manner using a $2 \times 6$ factorial design where the first factor was inoculation (I) [non-inoculated control and inoculated with $P$. ostreatus ] and the second factor was PAH composition (C) [Ace $\left(30 \mathrm{mg} \mathrm{kg}^{-1}\right.$ dry soil), $\mathrm{BaA}$ (30 $\mathrm{mg} \mathrm{kg}^{-1}$ dry soil), Ace (30 $\mathrm{mg} \mathrm{kg}^{-1}$ dry soil) $+\mathrm{BaA}$ (30 mg kg ${ }^{-1}$ dry soil), Ace (60 $\mathrm{mg} \mathrm{kg}^{-1}$ dry soil), BaA (60 mg $\mathrm{kg}^{-1}$ dry soil $)$ and Ace $\left(60 \mathrm{mg} \mathrm{kg}^{-1}\right.$ dry soil $)+\mathrm{BaA}(60 \mathrm{mg}$ $\mathrm{kg}^{-1}$ dry soil)]. Each treatment combination was run in triplicate. Boxes were incubated at $25^{\circ} \mathrm{C}$ in the dark.

\subsection{Extraction and analysis of PAHs}

Initial $\left(t_{0}\right)$ and final (after 15 days of incubation) concentrations of Ace and BaA were determined. Samples of $30 \mathrm{~g}$ were collected from each experimental unit. They were thoroughly homogenised and 10-g subsamples were mixed with an equal amount of $\mathrm{Na}_{2} \mathrm{SO}_{4}$ and subjected to automatic Soxhlet extraction (System B-811 from Buchi) for $2 \mathrm{~h}$ using a 1:1 mixture of acetone/n-hexane according with Environmental Protection Agency (EPA) method 3541 (US EPA 1994). The total extract was then concentrated by rotary evaporation $\left(<45{ }^{\circ} \mathrm{C}\right.$, $0.05 \mathrm{MPa}$ ) (Buchi RE 111 rotavapor with Buchi 961 water bath) to a volume of $3 \mathrm{ml}$. The residue extracts were further concentrated to near dryness under a gentle steam of high purity $\mathrm{N}_{2}$, and then redissolved in $5 \mathrm{ml}$ of acetonitrile. PAHs in acetonitrile were analysed with a high-performance liquid chromatography system (HPLC Pump Jasco Pu-1580 Quaternaries) equipped with a fluorescence detector (Jasco FP-920) and diode array detector (DAD) (Jasco MD-910). Analyses were performed using a Supelco C18 column (Supelcosil ${ }^{\mathrm{TM}}$ CC-PAH $4.6 \mathrm{~mm}$ i.d. $\times 250 \mathrm{~mm} \times 5 \mu \mathrm{m}$, pore size $100 \AA$ ). The mobile phase was methanol/water at 80:20\% $(v / v)$ in the first $5 \mathrm{~min}$ increasing between 5 and $10 \mathrm{~min}$ in a linear gradient to 95:5\% $(v / v)$ (methanol/water) with a flow rate of $1.0 \mathrm{ml}$ $\min ^{-1}$. BaA was detected by excitation wavelengths of 270 and $384 \mathrm{~nm}$ and Ace was detected by using the DAD.

\subsection{Chemicals}

$\mathrm{BaA}$ and Ace of 98 and $85 \%$ purity, respectively, were purchased from Sigma-Aldrich (USA). The PAHs solutions were prepared using acetone at $99.8 \%$ (Merck LiChrosolv, Germany). For the PAHs extraction from soil n-hexane at $98.2 \%$
(VWR, France), acetone at 99.8\% (Merck LiChrosolv, Germany) and acetonitrile at 99.9\% (Merck LiChrosolv, Germany) were used. In addition, the organic solvent for the HPLC analysis was methanol at 99.9\% (Merck LiChrosolv, Germany).

\subsection{Statistical analysis}

Normality and homogeneity of variances were confirmed and the data were analysed using two-way analysis of variance (ANOVA) for each dependent variable (initial and final PAHs concentrations) versus the independent variables [inoculation (I) and PAH composition (C)]. The biodegradation efficiencies data were arcsine transformed and compared using Student's $t$ test at a significance level of $P<0.05$. All statistical analyses were performed using the SPSS 20 software package (IBM SPSS Statistics, USA).

\section{Results and discussion}

3.1 Biodegradation of acenaphthylene and benzo[a] anthracene by Pleurotus ostreatus

P. ostreatus had an abundant growth with visible white mycelium evenly distributed on the soil in all experimental units, irrespective of PAH composition.

The PAHs recoveries at $t_{0}$ varied between 74.0 and $96.5 \%$ for Ace and between 90.7 and $98.3 \%$ for BaA. These recoveries were greater than previously reported by Song et al. (2002). They compared the recovery of PAHs from soils with varying abiotic properties, such as organic matter content, and obtained increased recovery in soils with lower organic matter content. In our study, a sandy soil with low organic matter was used, which reduced the potential for adsorption of PAHs onto the soil matrix. Also, the extraction process of PAHs was observed to be significantly more difficult from high-clay content soils when compared with sandy soils (Lau et al. 2010).

The PAHs recoveries in non-inoculated controls after 15 days of incubation calculated as the percentage of the measured initial $\left(t_{0}\right)$ concentration, varied between 77.0 and $84.3 \%$ for Ace, while that of $\mathrm{BaA}$ varied between 86.8 and $91.0 \%$. The fact that the recoveries of both PAHs were always less than $100 \%$ may be due to adsorption onto the soil matrix and/or incomplete extraction, as indicated by Majcherczyk et al. (1998), who obtained Ace recoveries of ca. $80 \%$ and $\mathrm{BaA}$ recoveries in the range of $85-100 \%$. The lower recoveries obtained for Ace in comparison with $\mathrm{BaA}$ after 15 days of incubation may be explained by different extraction efficiencies of these PAHs. Song et al. (2002) demonstrated that the number of rings significantly influenced recovery rates of 
Table 1 Initial $\left(t_{0}\right)$ and final (after 15 days of incubation) measured acenaphthylene concentrations and two-way ANOVA $F$ values according to inoculation and PAH composition factors

\begin{tabular}{|c|c|c|c|}
\hline Inoculation & PAH composition & $\begin{array}{l}\text { Initial Ace concentration } \\
\left(\mathrm{mg} \mathrm{kg}^{-1} \text { dry soil }\right)\end{array}$ & $\begin{array}{l}\text { Final Ace concentration } \\
\left(\mathrm{mg} \mathrm{g}^{-1} \text { dry soil }\right)\end{array}$ \\
\hline \multirow[t]{2}{*}{ Non-inoculated control } & Ace $\left(30 \mathrm{mg} \mathrm{kg}^{-1}\right.$ dry soil $)$ & $25.7 \pm 2.4$ & $19.8 \pm 2.5$ \\
\hline & Ace $\left(30 \mathrm{mg} \mathrm{kg}^{-1}\right.$ dry soil $)+\mathrm{BaA}\left(30 \mathrm{mg} \mathrm{kg}^{-1}\right.$ dry soil $)$ & $25.4 \pm 2.0$ & $21.4 \pm 2.0$ \\
\hline \multirow[t]{2}{*}{ Pleurotus ostreatus } & Ace $\left(30 \mathrm{mg} \mathrm{kg}^{-1}\right.$ dry soil $)$ & $24.4 \pm 2.1$ & $8.4 \pm 1.3$ \\
\hline & Ace $\left(30 \mathrm{mg} \mathrm{kg}^{-1}\right.$ dry soil $)+\mathrm{BaA}\left(30 \mathrm{mg} \mathrm{kg}^{-1}\right.$ dry soil $)$ & $22.2 \pm 2.9$ & $7.4 \pm 2.0$ \\
\hline Inoculation (I) & & $F=0.9 \mathrm{NS}$ & $F=40.6^{* * *}$ \\
\hline PAH composition (C) & & $F=0.3 \mathrm{NS}$ & $F=0.02 \mathrm{NS}$ \\
\hline $\mathrm{I} \times \mathrm{C}$ & & $F=0.2 \mathrm{NS}$ & $F=0.4 \mathrm{NS}$ \\
\hline \multirow[t]{2}{*}{ Non-inoculated control } & Ace $\left(60 \mathrm{mg} \mathrm{kg}^{-1}\right.$ dry soil $)$ & $55.5 \pm 2.9$ & $44.1 \pm 3.0$ \\
\hline & Ace $\left(60 \mathrm{mg} \mathrm{kg}^{-1}\right.$ dry soil $)+\mathrm{BaA}\left(60 \mathrm{mg} \mathrm{kg}^{-1}\right.$ dry soil $)$ & $55.0 \pm 2.2$ & $42.4 \pm 3.4$ \\
\hline \multirow[t]{2}{*}{ Pleurotus ostreatus } & Ace $\left(60 \mathrm{mg} \mathrm{kg}^{-1}\right.$ dry soil $)$ & $57.9 \pm 0.9$ & $15.4 \pm 3.5$ \\
\hline & Ace $\left(60 \mathrm{mg} \mathrm{kg}^{-1}\right.$ dry soil $)+\mathrm{BaA}\left(60 \mathrm{mg} \mathrm{kg}^{-1}\right.$ dry soil $)$ & $56.0 \pm 2.7$ & $12.2 \pm 2.0$ \\
\hline Inoculation (I) & & $F=0.5 \mathrm{NS}$ & $F=92.7 * * *$ \\
\hline PAH composition (C) & & $F=0.3 \mathrm{NS}$ & $F=0.6 \mathrm{NS}$ \\
\hline $\mathrm{I} \times \mathrm{C}$ & & $F=0.1 \mathrm{NS}$ & $F=0.1 \mathrm{NS}$ \\
\hline
\end{tabular}

$P A H$ polycyclic aromatic hydrocarbon, Ace acenaphthylene, $B a A$ benzo[a]anthracene $N S$ non-significant effect

***Significant effect at the level of $P<0.001$

individual PAHs from soils. In accordance with our results, Song et al. (2002) reported that the extraction efficiency of Ace, a 3-ring PAH, was lower than that of the 4ring $\mathrm{BaA}$.

In soil spiked with Ace at $30 \mathrm{mg} \mathrm{kg}^{-1}$ dry soil, inoculation with $P$. ostreatus significantly $(P<0.001)$ reduced the concentration of Ace after 15 days of incubation, when compared with non-inoculated controls (Table 1). The same effect was observed in soil spiked with Ace at $60 \mathrm{mg} \mathrm{kg}^{-1}$ dry soil. A similar biodegradation pattern was obtained for $\mathrm{BaA}$, i.e., in soil spiked with BaA at $30 \mathrm{mg} \mathrm{kg}^{-1}$ dry soil and at $60 \mathrm{mg} \mathrm{kg}^{-1}$ dry soil, inoculation with $P$. ostreatus significantly $(P<0.001)$ reduced the concentration of $\mathrm{BaA}$ after 15 days of incubation, when compared with non-inoculated controls (Table 2). These

Table 2 Initial $\left(t_{0}\right)$ and final (after 15 days of incubation) measured benzo[a]anthracene concentrations and two-way ANOVA $F$ values according to inoculation and $\mathrm{PAH}$ composition factors

\begin{tabular}{|c|c|c|c|}
\hline Inoculation & PAH composition & $\begin{array}{l}\text { Initial BaA concentration } \\
\left(\mathrm{mg} \mathrm{kg}^{-1} \text { dry soil) }\right.\end{array}$ & $\begin{array}{l}\text { Final BaA concentration } \\
\left(\mathrm{mg} \mathrm{kg}^{-1} \text { dry soil }\right)\end{array}$ \\
\hline \multirow[t]{2}{*}{ Non-inoculated control } & $\mathrm{BaA}\left(30 \mathrm{mg} \mathrm{kg}^{-1}\right.$ dry soil) & $29.5 \pm 0.3$ & $25.6 \pm 0.6$ \\
\hline & $\mathrm{BaA}\left(30 \mathrm{mg} \mathrm{kg}^{-1}\right.$ dry soil $)+$ Ace $\left(30 \mathrm{mg} \mathrm{kg}^{-1}\right.$ dry soil $)$ & $27.8 \pm 0.9$ & $25.3 \pm 1.2$ \\
\hline \multirow[t]{2}{*}{ Pleurotus ostreatus } & $\mathrm{BaA}\left(30 \mathrm{mg} \mathrm{kg}^{-1}\right.$ dry soil) & $27.2 \pm 1.9$ & $3.4 \pm 0.8$ \\
\hline & $\mathrm{BaA}\left(30 \mathrm{mg} \mathrm{kg}^{-1}\right.$ dry soil $)+$ Ace $\left(30 \mathrm{mg} \mathrm{kg}^{-1}\right.$ dry soil) & $28.4 \pm 0.3$ & $5.1 \pm 0.5$ \\
\hline Inoculation (I) & & $F=0.7 \mathrm{NS}$ & $F=685.1^{* * *}$ \\
\hline PAH composition (C) & & $F=0.1 \mathrm{NS}$ & $F=0.8 \mathrm{NS}$ \\
\hline $\mathrm{I} \times \mathrm{C}$ & & $F=1.8 \mathrm{NS}$ & $F=1.5 \mathrm{NS}$ \\
\hline \multirow[t]{2}{*}{ Non-inoculated control } & $\mathrm{BaA}\left(60 \mathrm{mg} \mathrm{kg}^{-1}\right.$ dry soil) & $57.8 \pm 1.2$ & $51.1 \pm 1.0$ \\
\hline & $\mathrm{BaA}\left(60 \mathrm{mg} \mathrm{kg}^{-1}\right.$ dry soil $)+$ Ace $\left(60 \mathrm{mg} \mathrm{kg}^{-1}\right.$ dry soil $)$ & $54.9 \pm 1.3$ & $49.1 \pm 1.0$ \\
\hline \multirow[t]{2}{*}{ Pleurotus ostreatus } & $\mathrm{BaA}\left(60 \mathrm{mg} \mathrm{kg}^{-1}\right.$ dry soil) & $56.7 \pm 2.4$ & $11.6 \pm 2.0$ \\
\hline & $\mathrm{BaA}\left(60 \mathrm{mg} \mathrm{kg}^{-1}\right.$ dry soil $)+$ Ace $\left(60 \mathrm{mg} \mathrm{kg}^{-1}\right.$ dry soil $)$ & $56.5 \pm 1.7$ & $14.4 \pm 2.8$ \\
\hline Inoculation (I) & & $F=0.02 \mathrm{NS}$ & $F=369.1 * * *$ \\
\hline PAH composition (C) & & $F=0.8 \mathrm{NS}$ & $F=0.1 \mathrm{NS}$ \\
\hline $\mathrm{I} \times \mathrm{C}$ & & $F=0.6 \mathrm{NS}$ & $F=1.6 \mathrm{NS}$ \\
\hline
\end{tabular}

$P A H$ polycyclic aromatic hydrocarbon, Ace acenaphthylene, $B a A$ benzo[a]anthracene $N S$ non-significant effect

*** Significant effect at the level of $P<0.001$ 


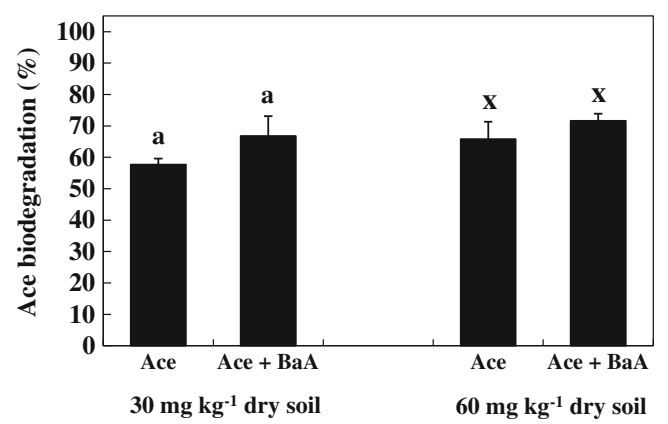

Fig. 2 Biodegradation efficiency (percentage of non-inoculated control after 15 days of incubation) of acenaphthylene by Pleurotus ostreatus. Columns marked with the same letters (" $a$ " for $30 \mathrm{mg} \mathrm{kg}^{-1}$ dry soil and " $x$ " for $60 \mathrm{mg} \mathrm{kg}^{-1}$ dry soil) are not significantly different according to Student's $t$ test at the level of $P<0.05$. Ace acenaphthylene; BaA benzo[a]anthracene

results indicate that $P$. ostreatus was capable of degrading both Ace and $\mathrm{BaA}$ irrespective of the initial tested soil concentration of these PAHs.

P. ostreatus was able to degrade $57.7 \%$ of the Ace in soil spiked at $30 \mathrm{mg} \mathrm{kg}^{-1}$ dry soil and $65.8 \%$ of the Ace in soil spiked at $60 \mathrm{mg} \mathrm{kg}^{-1}$ dry soil, after 15 days of incubation (Fig. 2). The degradation efficiency of BaA by P. ostreatus after 15 days of incubation was 86.7 and $77.4 \%$ in soil spiked with Ace at 30 and $60 \mathrm{mg} \mathrm{kg}^{-1}$ dry soil, respectively (Fig. 3).

The obtained degradation efficiencies of $\mathrm{BaA}$ are among the highest reported by $P$. ostreatus in soils. Andersson et al. (2003) showed that the degradation efficiency of BaA in soil was radically accelerated in the first 15 days, reaching $40 \%$. In a study with Pleurotus sp. in solid wheat straw substrate, Wolter et al. (1997) showed that by week 15 of incubation, the degradation efficiency of BaA was $25 \%$. Generally, lowmolecular weight PAHs possessing two or three aromatic rings, such as Ace are easily degraded, while those with high-molecular weight, such as BaA are significantly more recalcitrant in soils (Kanaly and Harayama 2000; Bhatt et al. 2002). However, in the present study, the tested P. ostreatus

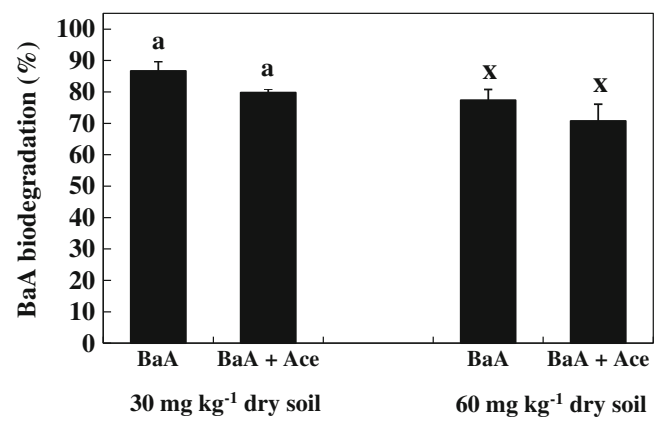

Fig. 3 Biodegradation efficiency (percentage of non-inoculated control after 15 days of incubation) of benzo[a]anthracene by Pleurotus ostreatus . Columns marked with the same letters (" $a$ " for $30 \mathrm{mg} \mathrm{kg}^{-1}$ dry soil and " $x$ " for $60 \mathrm{mg} \mathrm{kg}^{-1}$ dry soil) are not significantly different according to Student's $t$ test at the level of $P<0.05$. BaA benzo[a]anthracene; Ace acenaphthylene strain under our experimental conditions degraded $\mathrm{BaA}$ to a greater extent than Ace.

3.2 Influence of mixtures of acenaphthylene and benzo[a] anthracene on fungal degradation of PAHs

There were no significant differences in Ace concentration between soil spiked with Ace and soil spiked with Ace $+\mathrm{BaA}$ after 15 days of incubation, irrespective of the initial soil concentration of both PAHs (Table 1). The PAH composition factor did not influence the soil concentration of Ace nor did the interaction between inoculation and PAH composition factors. There were no statistical differences in Ace biodegradation efficiency between soil spiked with Ace and soil spiked with both PAHs at 30 and $60 \mathrm{mg} \mathrm{kg}^{-1}$ dry soil (Fig. 2). Similarly, there were no significant differences in $\mathrm{BaA}$ concentration between soil spiked with $\mathrm{BaA}$ alone and in combination with Ace for both tests of PAHs concentrations (Table 2). Soil concentration of BaA was not influenced by the PAH composition factor and there were no statistical differences in BaA biodegradation efficiency between soil spiked with $\mathrm{BaA}$ and soil spiked with both PAHs at 30 and $60 \mathrm{mg} \mathrm{kg}^{-1}$ dry soil (Fig. 3).

In most contaminated soils, the PAHs occur in complex mixtures. Therefore, it is necessary to assess the influence of mixtures of PAHs on their biodegradation. These influences include no significant impact; negative effects, including inhibition; and positive effects, including cometabolism (Beckles et al. 1998; Sang et al. 2009; Acevedo et al. 2011). Our data indicates that the presence of $\mathrm{BaA}$ did not significantly influence the fungal degradation of Ace in sandy soil and vice versa.

\section{Conclusions}

P. ostreatus was capable of degrading both Ace and $\mathrm{BaA}$ in soil at both tested concentrations. Under our experimental conditions, $P$. ostreatus degraded $\mathrm{BaA}$ to a greater extent than Ace. The degradation efficiencies of BaA by $P$. ostreatus were among the highest reported in soils. After 15 days of incubation there were no significant differences in Ace concentration between soil spiked with Ace and soil spiked with Ace $+\mathrm{BaA}$, irrespective of the initial soil concentration of both PAHs. There were also no differences in BaA concentration between soil spiked with $\mathrm{BaA}$ and soil spiked with $\mathrm{BaA}+$ Ace. These results indicate that the fungal degradation of Ace and $\mathrm{BaA}$ was not influenced by the presence of each other's PAH in sandy soil. Bioremediation of soils contaminated with Ace and $\mathrm{BaA}$ using $P$. ostreatus is a promising approach to eliminate these PAHs from the environment. 
Acknowledgments R.S. Oliveira wishes to acknowledge the support of Fundação para a Ciência e a Tecnologia through the research grant SFRH/ BPD/85008/2012 and Fundo Social Europeu.

\section{References}

Acevedo F, Pizzul L, Castillo MP, Cuevas R, Diez MC (2011) Degradation of polycyclic aromatic hydrocarbons by the Chilean white-rot fungus Anthracophyllum discolour. J Hazard Mater 185: 212-219

Andersson BE, Lundstedt S, Tornberg K, Schnürer Y, Öberg LG, Mattiasson B (2003) Incomplete degradation of polycyclic aromatic hydrocarbons in soil inoculated with wood-rotting fungi and their effect on the indigenous soil bacteria. Environ Toxicol Chem 22: $1238-1243$

Bakker MI, Casado B, Koerselman JW, Tolls J, Kolloffel C (2000) Polycyclic aromatic hydrocarbons in soil and plant samples from the vicinity of an oil refinery. Sci Total Environ 263:91-100

Bamforth SM, Singleton I (2005) Bioremediation of polycyclic aromatic hydrocarbons: current knowledge and future directions. J Chem Technol Biotechnol 80:723-736

Beckles DM, Ward CH, Hughes JB (1998) Effect of mixtures of polycyclic aromatic hydrocarbons and sediments on fluoranthene biodegradation patterns. Environ Toxicol Chem 17:1246-1251

Bhatt M, Cajthaml T, Šašek V (2002) Mycoremediation of PAHcontaminated soil. Folia Microbiol 47:255-258

Cajthaml T, Erbanová P, Šašek V, Moeder M (2006) Breakdown products on metabolic pathway of degradation of benz[a]anthracene by a ligninolytic fungus. Chemosphere 64:560-564

Gao D, Du L, Yang J, Wu WM, Liang H (2010) A critical review of the application of white rot fungus to environmental pollution control. Crit Rev Biotechnol 30:70-77

Haritash AK, Kaushik CP (2009) Biodegradation aspects of polycyclic aromatic hydrocarbons (PAHs): a review. J Hazard Mater 169:1-15

Johnsen AR, Wick LY, Harms H (2005) Principles of microbial PAHdegradation in soil. Environ Pollut 133:71-84

Kanaly RA, Harayama S (2000) Biodegradation of high-molecularweight polycyclic aromatic hydrocarbons by bacteria. J Bacteriol 182:2059-2067
Lau EV, Gan S, Ng HK (2010) Extraction techniques for polycyclic aromatic hydrocarbons in soils. Int J Anal Chem 2010(398381)

Majcherczyk A, Johannes C, Hüttermann A (1998) Oxidation of polycyclic aromatic hydrocarbons (PAH) by laccase of Trametes versicolor. Enzyme Microb Tech 22:335-341

Meharg AA, Wright J, Dyke H, Osborn D (1998) Polycyclic aromatic hydrocarbon (PAH) dispersion and deposition to vegetation and soil following a large scale chemical fire. Environ Pollut 99:29-36

Moody JD, Freeman JP, Cerniglia CE (2005) Degradation of benz[a]anthracene by Mycobacterium vanbaalenii strain PYR-1. Biodegradation 16:513-526

Nadal M, Schuhmacher M, Domingo JL (2004) Levels of PAHs in soil and vegetation samples from Tarragona County, Spain. Environ Pollut 132:1-11

Nayak AS, Veeranagouda Y, Lee K, Karegoudar TB (2009) Metabolism of acenaphthylene via 1,2-dihydroxynaphthalene and catechol by Stenotrophomonas sp. RMSK. Biodegradation 20:837-843

Riding MJ, Doick KJ, Martin FL, Jones KC, Semple KT (2013) Chemical measures of bioavailability/bioaccessibility of PAHs in soil: fundamentals to application. J Hazard Mater S0304-3894(13): 00220-00223

Rosales E, Pérez-Paz A, Vázquez X, Pazos M, Sanromán MA (2012) Isolation of novel benzo[a]anthracene-degrading microorganisms and continuous bioremediation in an expanded-bed bioreactor. Bioprocess Biosyst Eng 35:851-855

Rostami I, Juhasz AL (2011) Assessment of Persistent Organic Pollutant (POP) bioavailability and bioaccessibility for human health exposure assessment: a critical review. Crit Rev Env Sci Tec 41:623-656

Sang LZ, Wei XY, Chen JN, Zhu YZ, Zhang Y (2009) Simultaneous fluorimetric determination of the biodegradation processes of dissolved multi-component PAHs. Talanta 78:1339-1344

Song YF, Jing X, Fleischmann S, Wilke BM (2002) Comparative study of extraction methods for the determination of PAHs from contaminated soils and sediments. Chemosphere 48:993-1001

US EPA (1994) EPA Method 3541, Automated Soxhlet extraction. SW846, Test methods for evaluating solid waste, physical/chemical methods. United States Environmental Protection Agency

Wolter M, Zadrazil F, Martens R, Bahadir M (1997) Degradation of eight highly condensed polycyclic aromatic hydrocarbons by Pleurotus sp. Florida in solid wheat straw substrate. Appl Microbiol Biotechnol 48:398-404 